\title{
Evidence for Apoptotic Cell Death in Huntington Disease and Excitotoxic Animal Models
}

\author{
Carlos Portera-Cailliau, ${ }^{1,4}$ John C. Hedreen, ${ }^{1,2,4, a}$ Donald L. Price, ${ }^{1,2,3,4}$ and Vassilis E. Koliatsos ${ }^{1,2,3,4}$ \\ Departments of ${ }^{1}$ Neuroscience, ${ }^{2}$ Pathology, and ${ }^{3}$ Neurology and the ${ }^{4}$ Neuropathology Laboratory, The Johns \\ Hopkins University School of Medicine, Baltimore, Maryland
}

\begin{abstract}
Huntington disease (HD) is an inherited neurodegenerative disorder characterized by selective death of striatal medium spiny neurons. Intrastriatal injections of glutamate receptor agonists (excitotoxins) recapitulate some neuropathological features of this disorder. Although this model suggests that excitotoxic injury may be involved in HD, the exact mechanisms of cell death in HD and its models are unknown. The present study was designed to test the hypothesis that HD can develop via the activation of an apoptotic mechanism of cell death and to examine whether excitotoxic striatal lesions with quinolinic acid in rats represent accurate models of HD. To characterize cell death, we employed DNA electrophoresis, electron microscopy (EM), and the terminal transferase-mediated (TdT) deoxyuridine triphosphate (d-UTP)-biotin nick end labeling (TUNEL) method for the in situ detection of DNA strand breaks. In the neostriatum of individuals with HD, patterns of distribution of TUNEL-positive neurons and glia were reminiscent of those seen in apoptotic cell death during normal development of the nervous system; in the same areas, nonrandom DNA fragmentation was detected occasionally. Following excitotoxic injury of the rat striatum, internucleosomal DNA fragmentation (evidence of apoptosis) :vas seen at early time intervals and random DNA fragmentation (evidence of necrosis) at later time points. In addition, EM detected necrotic profiles of medium spiny neurons in the lesioned rats. In concert, these results suggest that apoptosis occurs in both HD and excitotoxic animal models and that apoptotic and necrotic mechanisms of neuronal death may occur simultaneously within individual dying cells in the excitotoxically injured brain. However, the distribution of dying neurons in the neostriatum, the degree of glial degeneration, and the involvement of striatofugal pathways are very different between HD and excitotoxically damaged
\end{abstract}

Received Sept. 9, 1994; revised Dec. 6, 1994; accepted Dec. 15, 1994.

We thank Drs. Christopher Ross, Lee Martin, and Stephen Ginsberg for helpful discussions. Dr. Lee Martin provided advice with the electron microscopy techniques. Mrs. Gloria Crisostomo assisted with the preparation of sections in the human cases. This study was supported by grants from the U.S. Public Health Service (NS 20471, AG 05146, NS 16735, NS 29484). Drs. Price and Koliatsos are the recipients of a Leadership and Excellence in Alzheimer's Disease (LEAD) award (NIA AG 07914) and a Javits Neuroscience Investigator Award (NIH NS 10580).

Correspondence should be addressed to Vassilis E. Koliatsos, M.D., Neuropathology Laboratory, The Johns Hopkins University School of Medicine, 558 Ross Research Building, 720 Rutland Avenue, Baltimore, MD 21205 2196.

Present address: New England Medical Center, Department of Psychiatry Boston, MA.

Copyright 1995 Society for Neuroscience $0270-6474 / 95 / 153775-13 \$ 05.00 / 0$ striatum. The present study suggests that multiple methods should be employed for a proper characterization of neuronal cell death in vivo.

[Key words: Huntington disease, excitotoxicity, programmed cell death, necrosis, neostriatum, endonuclease]

HD is an autosomal dominant disorder of midlife characterized by chorea and various psychiatric syndromes, including psychosis and dementia. The disorder is caused by the expansion of a CAG triplet repeat in the IT 15 gene located on chromosome $4 \mathrm{p}$ (Huntington's Disease Collaborative Research Group, 1993). The most consistent neuropathological abnormalities in HD occur in the neostriatum; the caudate nucleus and putamen become atrophic and show selective degeneration of medium spiny neurons (Vonsattel et al., 1985; Kowall et al., 1987). Intrastriatal injections of the glutamate receptor agonist kainic acid in rats appear to recapitulate some of the histopathological and neurochemical features of late-stage HD (Coyle and Schwarcz, 1976; McGeer and McGeer, 1976). Moreover, striatal injections of the $N$-methyl-D-aspartate (NMDA) receptor agonist quinolinic acid (QA) replicate the specific vulnerability of neostriatal cells in HD (i.e., destruction of medium spiny neurons with relative preservation of large somatostatin, neuropeptide $Y$, and cholinergic neurons) (Beal et al., 1986). Although these models suggest that excitotoxic injury may be implicated in the pathogenesis of HD, the exact pathophysiological mechanisms of cell death in this disease and their relationship to the altered IT15 gene product are unknown.

The two major types of cell death (i.e., apoptosis and necrosis) are differentiated on the basis of morphological abnormalities of cells at the ultrastructural level and patterns of DNA fragmentation on agarose gel electrophoresis. Apoptosis is characterized by membrane blebbing, perinuclear chromatin condensation, and organelle swelling, and by endonuclease-mediated internucleosomal DNA fragmentation into a "ladder" pattern. Necrosis is characterized by diffuse organelle swelling and lysis as well as random DNA fragmentation resulting in "smearing" of DNA on agarose gels (Kerr et al., 1972; Arends et al., 1990; Wyllie, 1980; Kerr and Harmon, 1991). The term "programmed cell death" (PCD) has been also used to describe the death of cells that occurs as part of normal development and morphogenesis in both vertebrates and invertebrates (Ellis et al., 1991; Oppenheim, 1991; Freeman et al., 1993). PCD is conventionally thought to occur through apoptosis, mediated by a $\mathrm{Ca}^{2+}$-dependent endonuclease (Arends et al., 1990; Schwartz et al., 1993), although in some classical examples of PCD, features of apoptosis have not been observed (Kerr and Harmon, 1991).

Many cases of cell death in vitro have been classified into 


\begin{tabular}{|c|c|c|c|c|c|c|}
\hline Case & Grade & Age/sex & $\begin{array}{l}\text { Duration } \\
\text { (years) }\end{array}$ & $\begin{array}{l}\mathrm{PMI}^{a} \\
\text { (hours) }\end{array}$ & TUNEL & Cells \\
\hline HD87 & 0 & $47 \mathrm{M}$ & 7 & $?$ & + & O only \\
\hline $\mathrm{HD} 24$ & 2 & $45 \mathrm{M}$ & 8 & 8 & - & \\
\hline HD 121 & 2 & $77 \mathrm{~F}$ & 16 & 14 & - & \\
\hline $\mathrm{HD} 40$ & 2 & $62 \mathrm{~F}$ & 25 & 8 & ++ & $\mathrm{N}>\mathrm{O}, \mathrm{A}$ \\
\hline HD1 12 & 3 & $69 \mathrm{M}$ & 18 & 6 & - & \\
\hline HD98 & 3 & $69 \mathrm{~F}$ & 24 & 6 & ++ & $\mathrm{N}>\mathrm{O}, \mathrm{A}$ \\
\hline HD108 & 3 & $76 \mathrm{M}$ & 28 & 3 & +++ & $\mathrm{N}>\mathrm{O}, \mathrm{A}$ \\
\hline HD39 & 3 & $84 \mathrm{~F}$ & 31 & 4 & + & $\mathrm{N}=\mathrm{O}, \mathrm{A}$ \\
\hline HDl01 & 3 & $76 \mathrm{~F}$ & 46 & 3 & ++ & $\mathrm{N}=\mathrm{O}, \mathrm{A}$ \\
\hline HD95 & 4 & $32 \mathrm{M}$ & 15 & 8 & + & $A, O>N$ \\
\hline 43767 & 4 & $49 \mathrm{~F}$ & 16 & 2 & - & no neurons left \\
\hline 47092 & 4 & $53 \mathrm{~F}$ & 16 & 5 & - & no neurons left \\
\hline 43915 & 4 & $54 \mathrm{M}$ & 29 & 8 & - & no neurons left \\
\hline 47727 & Control & $82 \mathrm{M}$ & & 7 & - & \\
\hline 43845 & Control & $58 \mathrm{~F}$ & & 17 & - & \\
\hline 47035 & Control & $44 \mathrm{~F}$ & & 3 & - & \\
\hline 47866 & Control & $66 \mathrm{M}$ & & 12 & - & \\
\hline 46645 & Control & $66 \mathrm{M}$ & & 10 & - & \\
\hline 48016 & Alzheimer & $86 \mathrm{~F}$ & & 6 & - & \\
\hline 46274 & Parkinson & $75 \mathrm{~F}$ & & 8 & - & \\
\hline 48073 & ALS & $70 \mathrm{M}$ & & 6 & - & \\
\hline
\end{tabular}

HD cases are listed both according to pathological grade and duration of disease. Grade 1 cases were not available for this study. TUNEL staining in the striatum was graded by two independent observers based on the number of TUNEL-positive cells $(+,++$, or +++$) ;-$, no TUNEL labeling observed. Abbreviations: $N$, neurons; $O$, oligodendrocytes; A, astrocytes; ALS, amyotrophic lateral sclerosis.

"Postmortem interval.

either apoptotic or necrotic types, but it is not clear whether these two processes are mutually exclusive. For example, in the nervous system, features of apoptosis may be present in some types of anoxic-ischemic injury, a classical type of necrotic cell death (Goto et al., 1990; Tominaga el al., 1993).

Although it has been suggested that neurodegenerative diseases may occur through the reactivation of PCD (Appel, 1981), to date, there is no direct evidence for either apoptotic or necrotic mechanisms that underlie pathological changes in these disorders. Because of its well-defined genetic cause, HD is likely to involve some type of PCD, as do several mouse mutants with retinal degeneration (Chang et al., 1993; PorteraCailliau et al., 1994). The present study was designed to clarify the mechanisms of cell death that occur in HD and to assess the degree to which excitotoxic striatal lesions in rats reproduce cell death in HD. Excitotoxic lesions have been classically considered to induce necrotic cell death, and predominant features of apoptosis, such as internucleosomal DNA fragmentation, have not been found in this setting (Ignatowicz et al., 1991; but see Kure et al., 1991). In the present study, we compared the pattern of DNA fragmentation (to distinguish between apoptotic and necrotic cell death) and the number, distribution, and types of cells undergoing DNA fragmentation between HD and the QA-lesioned rat striatum. To characterize cells with fragmented DNA, we used the recently developed TUNEL procedure (Gavrieli et al., 1992), which has been proposed as a specific method for in situ labeling of apoptotic cells. TUNEL has also been valuable in studying the distribution patterns and temporal course of neuronal cell death in some models (Chang et al., 1993; Veis et al., 1993; Portera-Cailliau et al., 1994; Rabacchi et al., 1994; Surh and Sprent, 1994; White et al.,
1994). EM was used in the QA model to characterize morphologically the type of cell death.

The results of the present study indicate that apoptosis may occur in some neurons and glia in the neostriatum in earlyintermediate stages of HD (based on TUNEL) and in early stages of the QA excitotoxic model (based on TUNEL and DNA laddering). Examination of the temporal relationships between DNA laddering and TUNEL in the QA excitotoxic model indicates that TUNEL labeling in degenerating neurons lasts longer than the putative duration of apoptosis. Taken together, the findings of the present study invite revisions in our current definitions of necrosis and apoptosis in the nervous system.

\section{Materials and Methods}

Human subjects. Tissues were obtained at autopsy from individuals with $\mathrm{HD}(n=13)$ and age-matched controls $(n=8)$, with postmortem delays ranging between 2 and $17 \mathrm{hr}$. Controls included cases without known neurological or psychiatric disease as well as cases with neurodegenerative diseases other than HD (e.g., Alzheimer disease, Parkinson disease, and amyotrophic lateral sclerosis) (Table 1). Postmortem pathological diagnosis confirmed the clinical diagnosis in each case. Pathological severity in each case of HD was graded based on the criteria of Vonsattel et al. (Vonsattel et al., 1985).

Animal subjects. Adult male Sprague-Dawley rats, weighing 200$250 \mathrm{gm}$, were used for QA injections. Animals were housed at $68-74^{\circ} \mathrm{F}$ on a 12:12 hr light:dark cycle; food and water were available ad libitum. All animal-related procedures were conducted in compliance with approved institutional protocols and in accordance with provisions for animal care and use, as described in the Guide for the Care and Use of Laboratory Animals (NIH publication 86-23, 1985).

$Q A$ injections. Injections were performed using standard procedures (Beal et al., 1989). Briefly, rats were anesthetized with a mixture of enflurane/nitrous oxide/oxygen. QA (Sigma, St. Louis, MO) was dissolved in $0.1 \mathrm{M}$ phosphate-buffered saline (PBS, pH 7.4) and kept in 

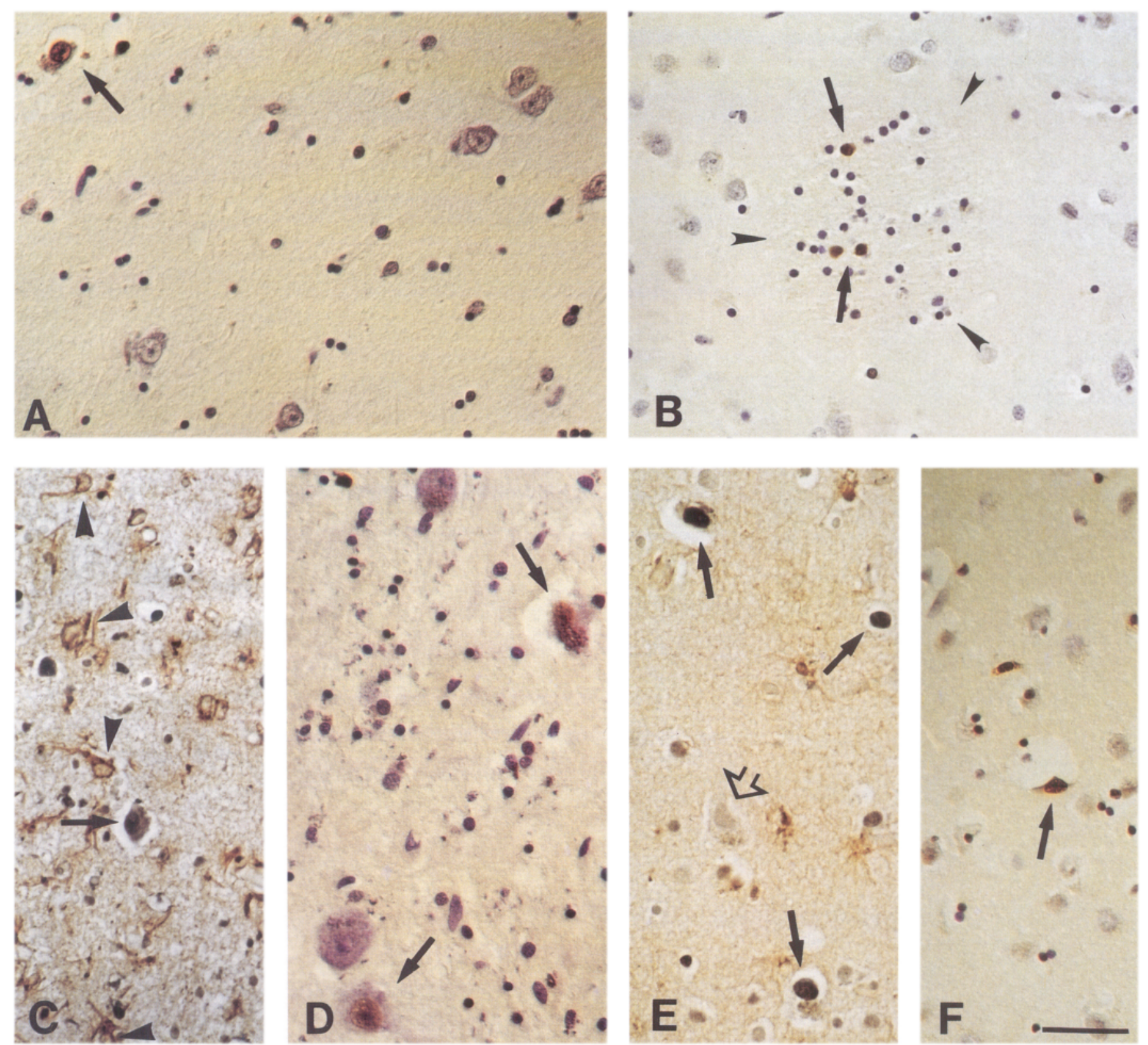

Figure 1. TUNEL staining in human tissues. $C$ and $E$ represent double labeling with TUNEL and GFAP. For double labeling, TUNEL was visualized with nickel-enhanced $\mathrm{DAB}$ and appears as a dark blue reaction product; GFAP was visualized with DAB and appears as a brown reaction product. In the remaining panels $(A, B, D$, and $F)$, DAB alone was used as the chromogen for TUNEL. Scale bar for all panels is $25 \mu \mathrm{m}$. $A-C$, Putamen from cases of HD. A shows a TUNEL-positive atrophic medium spiny neuron (arrow) interspersed with normal striatal neurons in grade $2 \mathrm{HD}$ (case HD40). B demonstrates oligodendrocyte labeling (arrows) within a striatopallidal pencil (demarcated by arrowheads) in a grade 0 case (HD87). Double-labeling histochemistry with GFAP in $C$ (case HD95) reveals no double-labeled astrocytes (arrowheads); a medium spiny neuron (GFAP negative) is indicated by the arrow. D, Globus pallidus pars externa from a case with HD (HD40). Arrows point to TUNEL-labeled atrophic pallidal neurons. E, Middle frontal cortex from a case with HD (HD101), showing TUNEL-labeled atrophic neurons in layer III (arrows); several GFAP-immunoreactive profiles are TUNEL negative. $F$, Basal forebrain with ischemic infarct (case 1091). Arrow indicates a TUNEL-stained neuron in the olfactory tubercle $(F)$.

the dark at $-20^{\circ} \mathrm{C}$ until used. Using a Hamilton microsyringe, QA (240 $\mathrm{nmol}$ in $0.5 \mu \mathrm{l}$ ) was injected into striatal targets corresponding to 0.5 $\mathrm{mm}$ anterior to bregma, $3.3 \mathrm{~mm}$ lateral to midline, and $4.5 \mathrm{~mm}$ ventral to dura. QA was injected over a $1 \mathrm{~min}$ period, and the needle was left in place for 5-7 min prior to slow withdrawal. Control animals $(n=$ $6)$ were injected with PBS alone and allowed to survive for $1(n=3)$ or $7(n=3)$ d postinjection.

The first group of animals $(n=21)$ was allowed to survive for the following periods: $4 \mathrm{hr}(n=2) ; 12 \mathrm{hr}(n=2) ; 16 \mathrm{hr}(n=2) ; 1 \mathrm{~d}(n$ $=3) ; 3 \mathrm{~d}(n=3) ; 5 \mathrm{~d}(n=3) ; 7 \mathrm{~d}(n=3)$; or $20 \mathrm{~d}(n=3)$. At appropriate times, animals were deeply anesthetized with sodium pentobarbital, i.p. $(100 \mathrm{mg} / \mathrm{kg}$ ) and then perfused transcardially with 700 $\mathrm{ml}$ of fresh $4 \%$ paraformaldehyde in PBS $(\mathrm{pH} 7.4)$ after a 1 min rinse with $1 \%$ paraformaldehyde in PBS. Brains were stored at $4^{\circ} \mathrm{C}$ in PBS until processed for paraffin embedding.

A second group of animals $(n=10)$ was allowed to survive for 10 , 12 , or $16 \mathrm{hr}, 1 \mathrm{~d}$, or $10 \mathrm{~d}$. At those times, animals were deeply anesthetized, as described above, and were decapitated. Fresh tissues from the injected and contralateral caudate-putamen and cortex around the needle track were subdissected for DNA extraction. 
A third group of animals ( $n=8$ ) was allowed to survive for $6 \mathrm{hr}$, $10 \mathrm{hr}, 14 \mathrm{hr}, 1 \mathrm{~d}$, or $3 \mathrm{~d}$. Animals were anesthetized, as described above, and were perfused for EM (see below).

TUNEL labeling of dying nerve cells. Paraffin sections ( $8 \mu \mathrm{m}$ thick) of human or rat tissues were mounted on Vectabond subbed slides (Vector Laboratories, Burlingame, CA), deparaffinized, and rehydrated. Sections were stained with the TUNEL method, essentially as described by Gavrieli et al. (Gavrieli et al., 1992). Sections were first treated with 20 $\mu \mathrm{g} / \mathrm{ml}$ proteinase $\mathrm{K}$ in $10 \mathrm{~mm}$ Tris $\mathrm{HCl}$ buffer ( $\mathrm{pH} 8.0$ ) for $15 \mathrm{~min}$ at room temperature (RT). Following a wash in double distilled water ( $\mathrm{ddH}_{2} \mathrm{O}$ ), endogenous peroxidase was inactivated in $3 \% \mathrm{H}_{2} \mathrm{O}_{2}$ for $5 \mathrm{~min}$ at RT. Sections were then washed in $\mathrm{ddH}_{2} \mathrm{O}$, incubated in TdT buffer (30 mM Tris $\mathrm{HCl}, \mathrm{pH} \mathrm{7.2;140} \mathrm{IIIM} \mathrm{sodium} \mathrm{cacodylate;} 1$ mM cobalt chloride) for $10 \mathrm{~min}$ at RT, and then incubated in TdT buffer containing $0.5 \mathrm{units} / \mathrm{ml}$ terminal transferase and $40 \mu \mathrm{M}$ biotinylated dUTP for $1 \mathrm{hr}$ at $37^{\circ} \mathrm{C}$ in a moist chamber. The reaction was stopped with $2 \times \mathrm{SSC}$ for 15 min at RT; sections were washed in PBS and then blocked in $2 \%$ bovine serum albumin (Sigma) in PBS for 10 min at RT. After a wash in ddH, 0 , sections were incubated for $1 \mathrm{hr}$ at $37^{\circ} \mathrm{C}$ in avidin/ peroxidase solution (Vectastain ABC Elite, mouse IgG, Vector Laboratories), washed in PBS, and then processed with a standard diaminobenzidine (DAB) chromogen reaction. Some sections were counterstained with cresyl violet, although others were saved for double-labeling histochemistry combining TUNEL with immunocytochemistry. Positive controls were incubated in $1 \mu \mathrm{g} / \mathrm{ml}$ DNase $\mathrm{I}$ in TdT buffer prior to incubation with biotinylated dUTP. Proteinase $K$, terminal transferase, biotin 16-dUTP, and DNase 1 were all purchased from BoehringerMannheim (Indianapolis, IN).

Double-labeling histochemistry for TUNEL and protein epitopes. To identify the types of nerve cells labeled by TUNEL, we carried out double-labeling histochemistry combining TUNEL with markers specific for neurons (nonphosphorylated neurofilaments), astrocytes [glial fibrillary acid protein (GFAP)], and oligodendrocytes [myelin basic protein (MBP)]. Selected paraffin sections of QA-treated rat brains or human striatum were first labeled with TUNEL using nickel enhanced DAB (Wouterlood et al., 1987) to produce a dark blue nuclear stain.

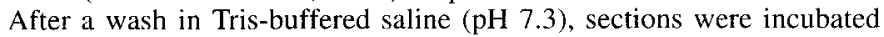
in $2 \%$ normal goat serum and $0.35 \%$ Triton $X-100$ in Tris-buffered saline for $1 \mathrm{hr}$. Sections were then incubated overnight with a polyclonal antibody to GFAP (Boehringer-Mannheim), a monoclonal antibody to nonphosphorylated neurofilaments (SMI-32; Sternberger Monoclonals, Inc., Jarrettsville, MD), or a monoclonal antibody to MBP (SMI-99, Sternberger Monoclonals) at appropriate dilutions (1:100 GFAP; 1:1,000 SMI-32, SMI-99). On the following day, sections were washed in Tris-buffered saline and incubated for $1 \mathrm{hr}$ in the appropriate secondary antibody (swine anti-rabbit for GFAP, goat anti-mouse for SMI32 and SMI-99), washed again, and incubated for 1 hr with mouse (1: $100)$ or rabbit (1:200) peroxidase-antiperoxidase. Sections were finally processed with a standard DAB chromogen reaction (brown reaction product). All incubations were done at $\mathrm{RT}$, and dilutions were made in $2 \%$ normal goat serum and $0.1 \%$ Triton X-100 in Tris-buffered saline except for the peroxidase-antiperoxidase step, which contained no Triton $\mathrm{X}-100$.

DNA labeling and gel electrophoresis. Fresh-frozen tissues from the dorsal putamen of the brains of cases of HD and controls, as well as fresh QA-injected and control rat striatal tissues, were homogenized in a DNA extraction buffer containing $0.1 \mathrm{mg} / \mathrm{ml}$ proteinase $\mathrm{K}, 100 \mathrm{~mm}$ $\mathrm{NaCl}, 10 \mathrm{~mm}$ Tris $\mathrm{HCl}(\mathrm{pH} 8.0), 25 \mathrm{~mm}$ EDTA $(\mathrm{pH} 8.0)$, and $0.5 \%$ SDS, and were incubated in the same buffer overnight at $50^{\circ} \mathrm{C}$. DNA was phenol-chloroform extracted, cthanol precipitated, and resuspended in $100 \mu \mathrm{l}$ of TE buffer (10 mM Tris, pH 7.6/1 mM EDTA, pH 8.0). DNA was incubated for $1 \mathrm{hr}$ (RT) in $0.1 \mathrm{mg} / \mathrm{ml}$ RNase (BoehringerMannheim) and then incubated overnight at $37^{\circ} \mathrm{C}$ in proteinase $\mathrm{K}(0.1$ $\mathrm{mg} / \mathrm{ml}$ ). DNA was reextracted, reprecipitated, and resuspended in $20 \mu \mathrm{l}$ TE buffer. For control apoptotic ladders, DNA was isolated from pigment epithelium-free mouse retinas at postnatal days 10 and 19 (PorteraCailliau et al., 1994).

DNA was labeled with terminal transferase and digoxigenin dd-UTP using the Genius ${ }^{(\overline{T M}}$ system (Boehringer-Mannheim), as recommended by the manufacturer. DNA $(\sim 0.1-1.0 \mu \mathrm{g})$, fractionated in a $1.5 \%$ agarose gel, was transferred to a nylon membrane that was first treated with a $2 \%$ nucleic acid blocking reagent solution and then incubated with an anti-digoxigenin antibody conjugated to alkaline phosphatase (diluted $1: 10,000$ in the blocking solution). Labeled DNA was visualized by incubating the membrane with Lumi-Phos 530 (Boehringer-Mann- heim). The nylon membrane was exposed to Kodak X-OMAT AR film (Eastman Kodak, Rochester, NY) for an appropriate darkness of the digoxigenin-labeled molecular weight marker (5-10 min).

Electron microscopy. QA-injected animals were anesthetized with sodium pentobarbital (100 $\mathrm{mg} / \mathrm{kg}$, i.p.) and then perfused with $150 \mathrm{ml}$ of fresh $1 \%$ paraformaldehyde including $0.1 \%$ glutaraldehyde in $0.1 \mathrm{M}$ phosphate buffer ( $\mathrm{pH} 7.4$ ), followed by $350 \mathrm{ml}$ of $2 \%$ paraformaldehyde with $2 \%$ glutaraldehyde in same buffer. The brain was postfixed overnight at $4^{\circ} \mathrm{C}$ in the latter fixative. The striatum was subdissected into 1 $\mathrm{mm}^{3}$ blocks washed in PB and then treated with $2 \%$ osmium tetroxide in $0.1 \mathrm{M}$ phosphate buffer for $2 \mathrm{hr}$ at RT. Blocks were washed in the same buffer, dehydrated, and embedded in Epon. Thin sections (gold interference color) were cut, stained with uranyl acetate and lead citrate, and viewed with a Phillips CM12 electron microscope.

Mapping and quantitative analysis. The mapping and quantitative assessment of TUNEL-positive cells in human striatum was performed using a Zeiss Axiophot microscope coupled to an electronic stage encoder (Minnesota Datametrics, St. Paul, MN) and a video camera, all connected to an AT-compatible computer equipped with a pen plotter (7475A, Hewlett-Packard, Corvallis, OR); software was a gift from Dr. Mark E. Molliver (Department of Neuroscience. The Johns Hopkins University School of Medicine, Baltimore, MD) and was adapted for use in our laboratory by Ms. Catherine Fleischman (Neuropathology Laboratory).

To analyze the distribution of dying nerve cells in striatum, we plotted all TUNEL-positive cells in coronal sections of neostriatum at the level of the decussation of the anterior commissure of HD cases of grades $0,2,3$, and 4 . Plotting was done under $40 \times$ magnification.

Quantitative analys1s focused on densities of TUNEL-labeled medium spiny neurons in human neostriatum. Using the same computerized mapping system, a grid of $36 \mathrm{~mm}^{2}$ square boxes was overlaid on computer-generated images of the striatum using sections from each HD brain taken through the commissural decussation. TUNEL-positive and -negative medium spiny neurons were counted in the central portion of every other box (i.e., the portion transferred on to the computer screen when the box was viewed under $40 \times$ magnification, corresponding to a field $260 \times 165 \mu \mathrm{m}$ ) (see Fig. $2 C$ ). Percentages of TUNEL-positive medium spiny neurons were calculated, and percentage averages from all three sections were generated per HD case.

\section{Results}

\section{TUNEL labeling in $H D$}

Observations were based on the brains from cases of HD with varying grades of pathology (grades $0-4$ ) as compared to tissues from healthy controls or cases with other neurodegenerative disease that were matched for age (Table 1). TUNEL-labeled cells were detected in the striatum of many brains with HD (Fig. 1A). Neurons were labeled in one of three grade 2 cases, four of five grade 3 cases, and one of four grade 4 cases (Table 1). In one grade 0 case, we observed TUNEL labeling of oligodendrocytes but not neurons (Fig. 1B). Cases of grade 1 were not available for examination. In grades 3 and 4, the most intense labeling was seen in cells of the putamen, followed by cells of the globus pallidus (Fig. $1 D$ ) and caudate nucleus (Fig. 2A.B). A striking dorsoventral pattern of TUNEL labeling was seen in the putamen, with dorsal regions showing much higher densities of TUNEL-labeled nerve cells than areas in the midputamen; minimal labeling was seen in ventral putamen, particularly in early stages (Fig. $2 A, B$ ). The temporal progression of TUNEL staining in the caudate nucleus resembled that seen in dorsal putamen, with increasingly higher percentages of TUNFI -positive neurons in higher grades.

In grades 2 and 3, many more neurons were labeled than glial cells; however, in grade 4 , in which there are few surviving medium spiny neurons in the neostriatum (Vonsattel et al., 1985), the vast majority of TUNEL-positive nuclei belong to glia. Based on the morphological characteristics and locations of TUNEL-labeled cells (Fig. $1 B$ ) as well as on the lack of colocalization of TUNEL with GFAP (Fig. 1C), glial staining 

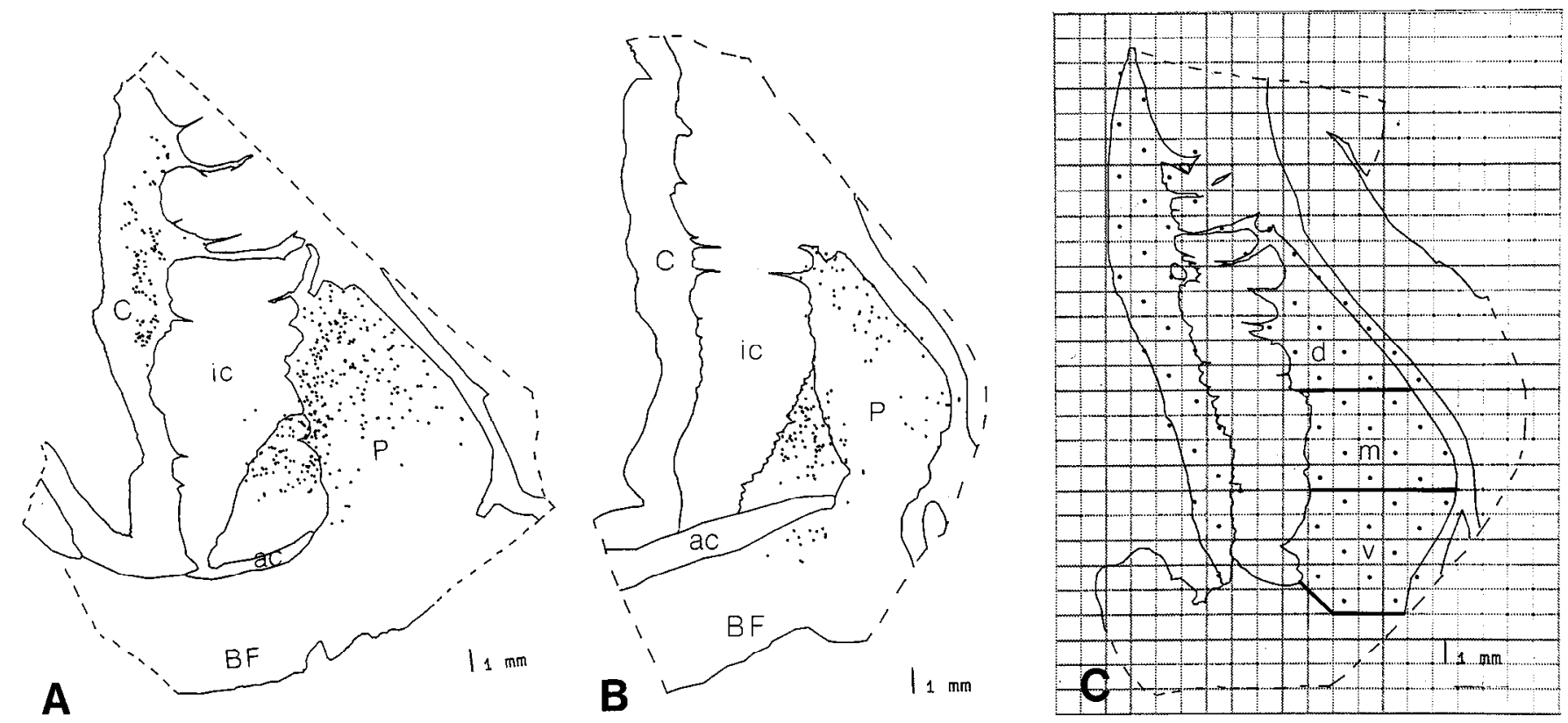

Figure 2. Maps of TUNEL-labeled nerve cells in representative striatal sections in HD $(A$ and $B)$ and method for measuring densities of TUNELlabeled neurons in these tissues $(C)$. All sections are taken at or just rostral to the level of the decussation of the anterior commissure (the plane at which densities of TUNEL-positive cells were measured). Abbreviations: $C$, caudate; $P$, putamen; $B F$, basal forebrain; $i c$, internal capsule; $a c$, anterior commissure; $d$, dorsal; $m$, middle; $v$, ventral putamen. $A$ and $B$, The distribution of TUNEL-positive cells favors the caudate nucleus and dorsal aspects of putamen: this pattern holds true in both intermediate ( $A$, grade 3 , HD101) and advanced $(B$, grade 4, HD95) cases of HD, although labeling in $B$ is sparser. $C$, In control sections, a grid of identical square boxes is overlaid on a section taken through the same plane as in $A$ and $B$. Dotted boxes indicate the areas where neurons were counted under a high-power lens $(40 \times)$. To enhance clarity, a larger grid than the one used for counts is shown (see Experimental Procedures).

primarily involved oligodendrocytes. Many labeled oligodendrocytes were located within bundles of striatopallidal fibers (pencils of Wilson) (Fig. $1 B$ ).

TUNEL staining was also present in neurons in most layers of middle frontal cortex from grade 3 subjects that showed robust TUNEL labeling in putamen (Fig. 1E). Labeling was not sccn in the ccrcbcllum, thalamus, pons, visual cortex, or mid brain in grade 3 cases of HD. In addition, TUNEL labeling was not found in the striata of age-matched control cases or cases of Alzheimer disease, Parkinson disease, or amyotrophic lateral sclerosis.

Densities of TUNEL-positive neuronal profiles were estimated on individual grade $3 \mathrm{HD}$ cases based on a systematic random sampling of neurons within square grids overlaid on the striatum. On average, $\sim 6 \%$ of medium spiny neurons were labeled in the caudate, and $\sim 3 \%$ of neurons were labeled in putamen $(10 \%$ of medium spiny neurons in the dorsal putamen, $5 \%$ in the midputamen, and $<1 \%$ in the ventral putamen). It should be taken into consideration that the total number of medium spiny neurons is reduced in HD and that this reduction is especially prominent in the dorsal striatum.

It is unlikely that the degree of TUNEL labeling in HD cases was influenced by postmortem autolysis, as there was no indication of increased TUNEL staining with longer postmortem intervals (Table 1). To investigate directly the effects of postmortem autolysis on TUNEL staining in tissues containing degenerating neurons, we used the brains of 2-week-old rat pups (a time of pronounced developmental death of striatal neuroepithelial cells) that were maintained at RT over periods of time comparable to those of postmortem intervals of human cases. Numbers of TUNEL-stained cells from striatal neuroepithelium in perfused brains were comparable to those in brains of littermates left for $6 \mathrm{hr}$ at RT prior to immersion fixation (data not shown).

\section{TUNEL labeling and EM analysis in the QA injected neostriatum}

Tissue sections were stained using the TUNEL method at different rostrocaudal levels of QA-injected neostriata from rats killed $4 \mathrm{hr}$ to $20 \mathrm{~d}$ after QA injection. At $3 \mathrm{~d}$ postinjection, there was extensive labeling of nuclei throughout the lesioned striatum (Fig. $3 B$ ), but no labeling in the contralateral striatum (Fig. $3 A, C)$ or in PBS-injected animals. Nearly all medium spiny neurons were affected near the injection site, whereas, peripheral to the injection, labeled medium spiny neurons were interspersed with unlabeled healthy neurons (Fig. $3 D$ ). Among other brain regions peripherally involved in the QA injection, the endopiriform nucleus and thalamus contained a variable number of TUNEL-labeled neurons (not shown). In contrast, cells in the globus pallidus did not show labeling (Fig. $3 B$ ).

Staining of sections with the antibody SMI-32, which recognizes nonphosphorylated neurofilament proteins, demonstrated degenerating immunoreactive axons in the striatopallidal axonal bundles on the injected side (Fig. compare $3 C, D$ ). The above finding is evidence that TUNEL-labeled neurons in the QAtreated striatum are undergoing degeneration.

To study the temporal progression of cell death, rats were sacrificed at different times postinjection ranging from $4 \mathrm{hr}$ to 3 weeks (see Experimental Procedures). 'TUNEL labeling became evident at $12 \mathrm{hr}$ and disappeared by $7 \mathrm{~d}$. At $12 \mathrm{hr}$, faintly labeled nuclei were confined to a region of neostriatum surrounding the needle track. By $1 \mathrm{~d}$ postinjection, TUNEL-labeled neurons were 

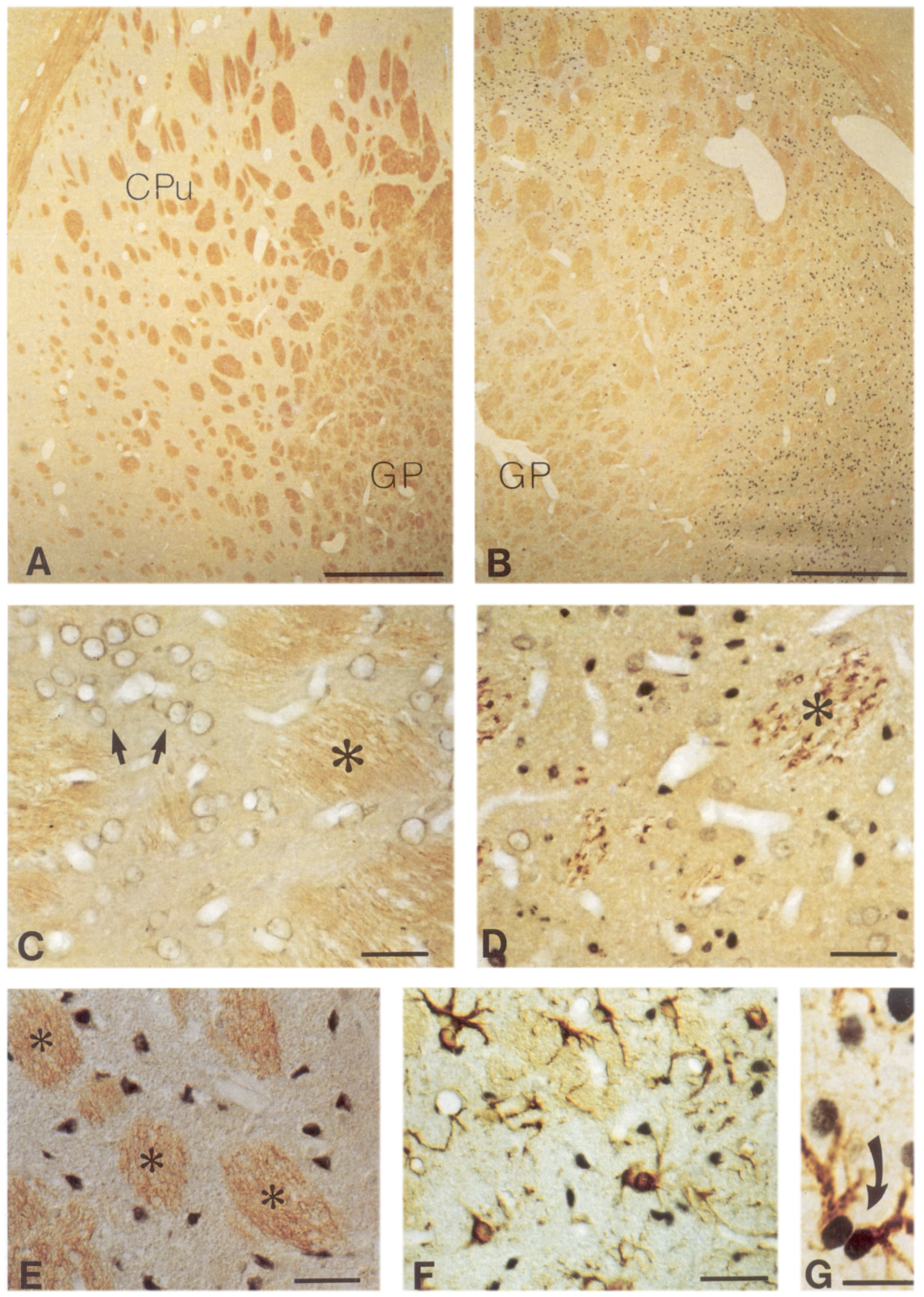
uniformly distributed throughout the neostriatum; labeling intensity appeared to peak at $3 \mathrm{~d}$ postinjection. By $5 \mathrm{~d}$, labeling was significantly reduced at the injection site, although some nuclei in the periphery were labeled intensely.

Double-labeling histochemistry with TUNEL and antibodies to GFAP or MBP was employed to assess whether cells other than neurons (i.e., astrocytes and oligodendrocytes, respectively) were labeled by TUNEL in the QA model. TUNEL labeling was not seen in GFAP-positive astrocytic profiles (Fig. $3 F$ ) or within MBP-immunoreactive profiles of oligodendrocytes within the neostriatal white matter bundles (Fig. $3 E$ ). The lack of double labeling was not an artifact of the technique because we were able to double label astrocytes with both GFAP inmunoreactivity and TUNEL staining in DNase-treated material (Fig. 3G).

Ultrastructural study of the QA-injected rat striatum was used as an independent method to characterize morphologically the cell death process in this model of neurodegeneration. Control and QA-injected striatal blocks from rats perfused at different times following the injection (ranging from $6 \mathrm{hr}$ to $3 \mathrm{~d}$ ) were examined. At $6 \mathrm{hr}$ postinjection, ultrastructural alterations were already evident in some cells, including neurons, in the injected striatum; a large number of cells was affected by $10 \mathrm{hr}$. Affected neurons contained large clumps of chromatin within nuclei as well as numerous vacuoles and swollen organelles in the cytoplasm, although perikaryal synapses were characteristically intact, including identifiable postsynaptic densities (Fig. 4A,B). A subset of neurons was severely affected, showing evidence of membrane disintegration with no recognizable synapses and severely distorted organelles; these neurons were especially abundant near the injection site and became evident as early as $6 \mathrm{hr}$ postinjection (Fig. 4C). Apoptotic neuronal profiles with peripherally condensed nuclear chromatin and relatively intact organelles were not observed. By $14 \mathrm{hr}$ postinjection, the injected striatum contained large numbers of phagocytic cells internalizing neuronal debris (Fig. 4D).

\section{Patterns of DNA fragmentation in the $Q A$ model and $H D$}

To confirm the apoptotic nature of the cell death that occurs in HD and in the QA-injected rat striatum, we studied fragmentation patterns of DNA isolated from human and rat striatal tissues using agarose gel electrophoresis. This method allows the distinction between apoptotic "laddering" of DNA into internucleosomal fragments and necrotic "smearing" of DNA into random-size fragments. In QA-injected rats, DNA was isolated from the entire caudate-putamen as well as from the area of cortex traversed by the needle track; the contralateral striatum was used as a control. In HD, the brains of individuals with grades 3 and 4 were used, together with age-matched controls.
DNA was isolated from the dorsal putamen (the area of neostriatum with the highest density of TUNEL labeling in HD).

DNA isolated from the QA-lesioned rat striatum at 10,12 , or $16 \mathrm{hr}$ postinjection (corresponding to the beginning of TUNEL labeling) migrated as a ladder of fragments corresponding in size to multiples of 180-200 base pairs (Fig. 5A, lanes 1-3). This migration pattern is identical to that of DNA isolated from rat retina undergoing developmental apoptosis (Fig. 5A, lane 7). However, the relative quantity of large vs. small DNA fragments, as evidenced by the intensity of the corresponding bands on the gel, was different in each case. In the QA-injected striatum, large DNA fragments predominated over small ones, whereas in the developing retina, the smaller fragments (in particular, mono- and dinucleosomal bands) were more pronounced. DNA from the contralateral striatum did not show any fragmentation $16 \mathrm{hr}$ postinjection (Fig. $5 A$, lane 4). DNA prepared from a portion of cortex around the needle tract also showed laddering at $12 \mathrm{hr}$ (lane 5) and at $16 \mathrm{hr}$ postinjection (not shown). However, DNA isolated from the lesioned striatum $1 \mathrm{~d}$ after the QA injection showed a random DNA degradation resulting in a smear of labeled DNA (lane 8); such a smear was absent in DNA isolated from the contralateral striatum (lane 9) or from the ipsilateral cerebellum (lane 11). DNA isolated from cortex around the needle tract at $1 \mathrm{~d}$ postinjection also showed random degradation (not shown). DNA isolated from the striatum $10 \mathrm{~d}$ after the QA injection (when there is no more TUNEL labeling) did not show evidence of fragmentation (lane 10).

In $\mathrm{HD}$, there was a variety of DNA degradation profiles, although, in the majority of cases, DNA was relatively intact (Fig. $5 B$, lanes 4,5 ). Despite the fact that no DNA samples from HD cases migrated as a classical apoptotic ladder, some grade 3 cases did show evidence of nonrandom DNA fragmentation (lane 6, arrows). Control samples from the striatum of healthy controls rarely showed any evidence of DNA degradation (Fig. $5 B$, lane 3 ).

To demonstrate that it is possible to detect DNA laddering in postmortcm human brain, wc isolated and electrophoresed DNA from the region of an ischemic infarct at $1-2 \mathrm{~d}$ postinfarct survival. This region (globus pallidus-basal forebrain) contained many TUNEL-labeled cells on histological sections (Fig. $1 F$ ). Migration patterns of this DNA sample were consistent with laddering, comparable to that of DNA from retinas undergoing PCD (Fig. 5B, lanes 7,8). The above electrophoresis pattern of human DNA was not significantly affected by postmortem autolysis, because DNA isolated from rat brains kept postmortem for $6 \mathrm{hr}$ at RT did not show evidence of degradation (Fig. $5 B$, lanes 1, 2).

\section{$\leftarrow$}

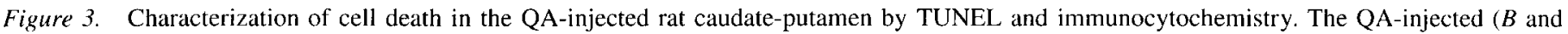

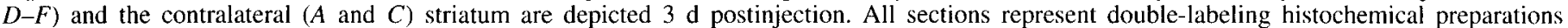

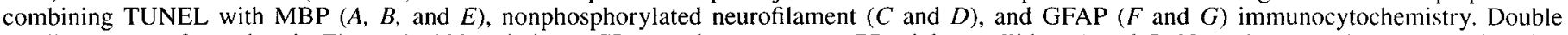

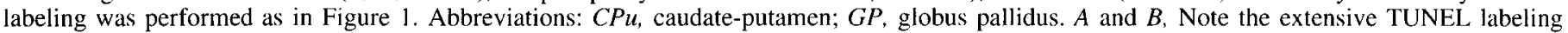

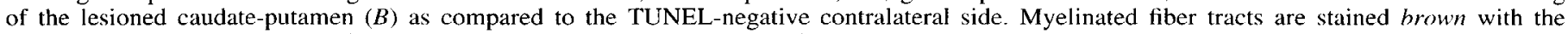

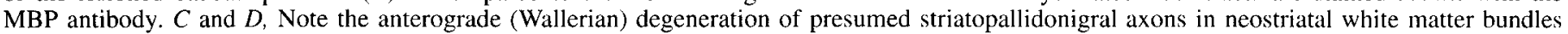

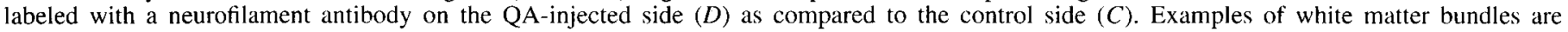

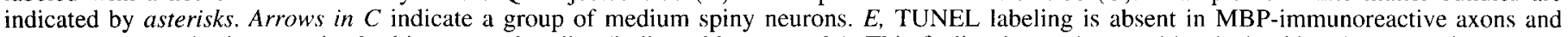

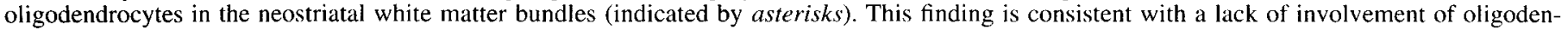

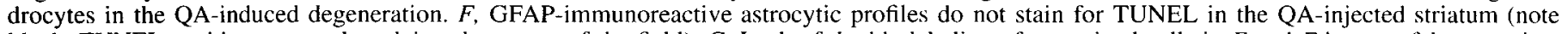

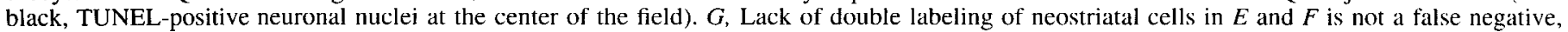
because GFAP-positive astrocytes stain for TUNEL in this DNase-pretreated section. Scale bars: $A$ and $B, 250 \mu m ; C-G, 25 \mu m$. 

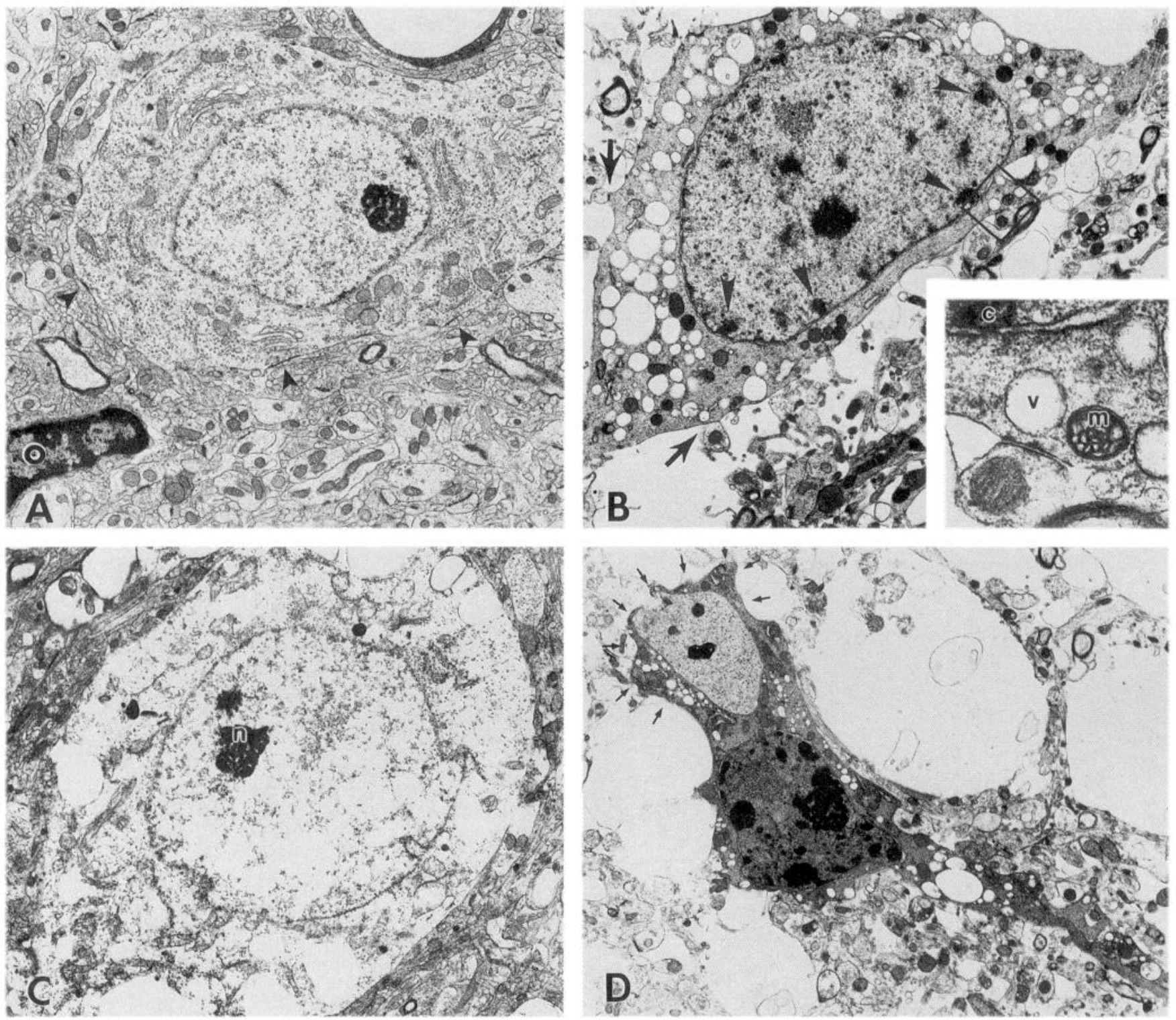

Figure 4. Morphological characterization of cell death in the QA-lesioned striatum. Thin sections are taken from a QA-injected caudate-putamen $(B-D) 10 \mathrm{hr}$ postinjection as well as from the contralateral neostriatum $(A)$. A, Normal neuron with clearly identifiable synapses $($ arrows $)$ and a perineuronal oligodendrocyte $(o) . B$ and $C$, At $10 \mathrm{hr}$ postinjection, necrotic changes such as chromatin condensation (arrowheads) and diffuse vacuolization (see inset, v) are apparent. Most organelles including endoplasmic reticulum and mitochondria (see inset, $25,000 \times$ ) are swollen but synapses (arrows, see inset) are clearly discernible. In a subset of neurons gross vacuolization with membrane disintegration is apparent (in $C, n$ $=$ nucleolus). $D, \mathrm{~A}$ phagocytic cell engulfing cellular debris (arrows), presumably originating in dying neurons. Magnification: $4000 \times$.

\section{Discussion}

The present study was designed to test the hypothesis that inherited neurodegenerative diseases, such as HD, can occur via a reactivation of apoptotic mechanisms of cell death and to test whether excitotoxic striatal lesions in rats represent reliable models of HD. In addition to DNA agarose gel electrophoresis and EM, the TUNEL method was used to detect in situ DNA fragmentation at the single-cell level. Distribution patterns of TUNEL-labeled neurons and glia in the striatum in HD are suggestive of apoptosis. In contrast, the finding that apoptotic DNA laddering occur in early stages of excitotoxic injury but that necrotic morphologies are seen by EM suggests that either DNA laddering is a step common to all types of cell death or that both apoptetic and necrotic mechanisms may occur simultaneously in excitotoxic cell death. Taken together, these results invite im- portant revisions of our current definitions of necrosis and apoptosis in the nervous system. In addition, despite some wellknown similarities between excitotoxic animal models and HD, this study raises concerns about the validity of these models in the study of HD with respect to the mechanisms of the degeneration and the cell types involved.

\section{Cell death in $H D$}

Several features of the cell death that occurs in HD, as described herein, are consistent with an apoptotic mechanism. In contrast to necrosis, in which whole patches of cells usually die rapidly and synchronously after an exogenous insult (see section on QA model), in HD, TUNEL staining is seen in isolated medium spiny neurons. Both the slow time course of progression and the multifocal single-cell death patterns in HD are consistent with 
A

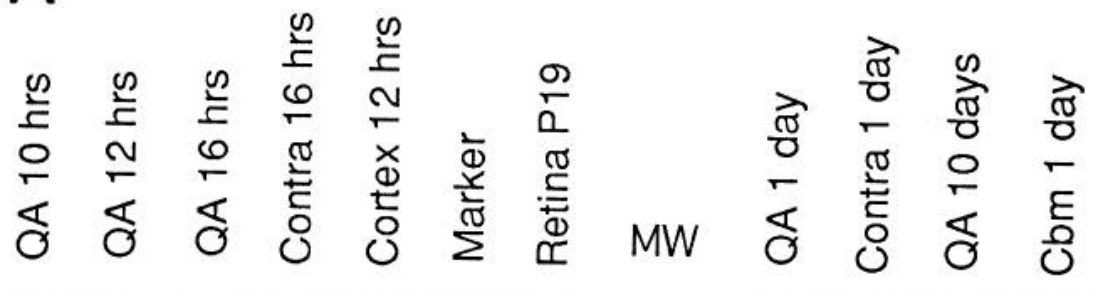

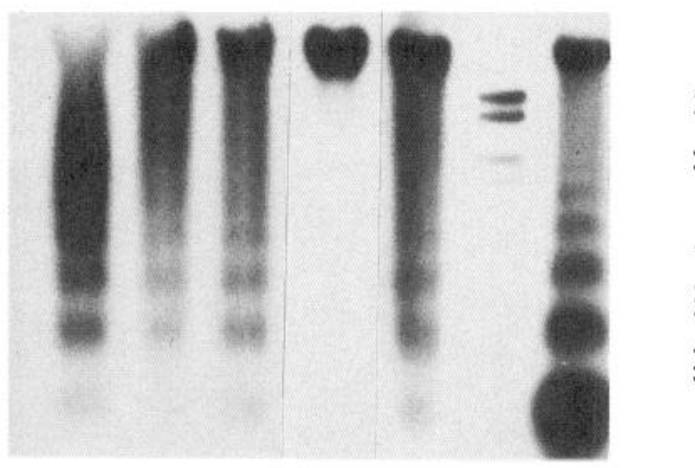

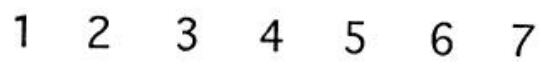

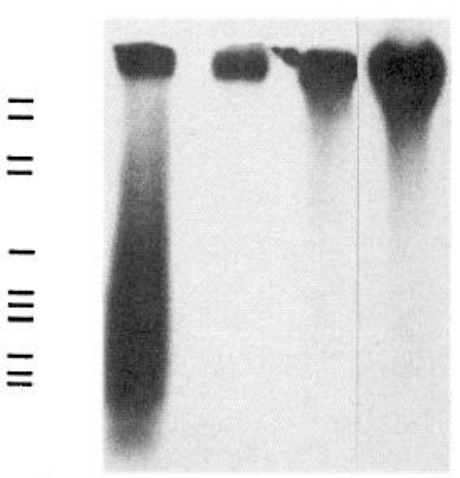

$\begin{array}{llll}8 & 9 & 10 & 11\end{array}$
Figure 5. Molecular characterization of striatal cell death in HD and the QA model based on DNA fragmentation patterns on gel electrophoresis. Molecular weight $(M W)$ markers: fragments of $2176,1766,1230,1033,653,517$, $453,394,298,234$, and 220 base pairs. $A$, Patterns of DNA migration from QA-injected striatum. DNA was isolated from lesioned striatum at various time points postinjection, including 10 , 12 , and $16 \mathrm{hr}$ (lanes 1-3), $1 \mathrm{~d}$ (lane 8), and $10 \mathrm{~d}$ (lane 10). Negative control DNA was isolated from contralateral striatum at $16 \mathrm{hr}$ (lane 4) and $1 \mathrm{~d}$ (lane 9) postinjection as well as from ipsilateral cerebellum $1 \mathrm{~d}$ postinjection (lane 11). Control apoptotic ladder of DNA (lane 7) represents developmental cell death in the mouse retina at postnatal day 19. DNA was also isolated from a portion of cortex surrounding the needle tract (lane 5). B, Patterns of DNA migration in HD striatum. Technical controls, to show that short postmortem delays do not alter DNA migration patterns, are shown in lanes 1-2 and represent DNA isolated from a 2-week-old control rat brain (lane l) and from a 2-week-old rat brain that was left at RT for $6 \mathrm{hr}$ prior to DNA extraction (lane 2). Lanes 4-6 correspond to DNA isolated from the striatum of three representative HD cases. Grades of HD patients are indicated in parentheses. Negative control DNA was isolated from the striatum of a normal human brain (lane 3). A control apoptotic ladder of DNA (lane 7) represents developmental cell death in the mouse retina at postnatal day 10 . Another positive control DNA was isolated from the globus pallidus of a patient with a basal forebrain ischemic infarct involving this nucleus (lane 8 ). an apoptotic mechanism triggered within affected cells. Identical patterns of TUNEL labeling consistent with apoptosis have been described in retinal degenerations of genetic origin (PorteraCailliau et al., 1994).

The finding that few cells were labeled by TUNEL and that these cells were interspersed among many unlabeled cells may explain why nonrandom DNA fragmentation was not observed in many cases of HD. Even though a sensitive method for the detection of DNA fragmentation on agarose gels was used, DNA fragments may have been present but were below the limit of detection. Generally, it is difficult to detect DNA fragmentation in tissues with limited TUNEL staining. For example, in the developing retina, where TUNEL can detect DNA fragmentation in isolated dying cells, DNA laddering is not seen by agarose gel electrophoresis (Portera-Cailliau et al., 1994).

The fact that apoptosis has often been associated with programmed cell death (Gavrieli et al., 1992; Obeid et al., 1993; Peitsch et al., 1993; Rabacchi et al., 1994) suggests that a genetic 
program of cell death may be activated in HD. However, because it is nearly impossible to gather evidence of prevention of cell death by macromolecular synthesis inhibitors or other evidence of novel gene expression in the context of postmortem human tissue, we cannot yet conclude that PCD occurs in HD. Moreover, the features of DNA fragmentation presented here cannot definitively rule out a possible necrotic mechanism triggered by a pathogenetic course of events intrinsic to individual neurons that makes these cells vulnerable to excitotoxic injury.

In addition to dying neurons, the TUNEL method also detected dying oligodendrocytes in the striatum at different grades of HD severity. There are two possible explanations for this observation. One possibility is that neuronal death and subsequent Wallerian degeneration of axons result in secondary cell death of oligodendrocytes. Alternatively, oligodendrocytes may die as a direct result of the genetic alteration in the IT-15 gene, as do medium spiny neurons.

Although neuronal death in HD occurs continuously over many years, we present evidence that the number of neostriatal neurons concurrently undergoing cell death is not constant throughout the course of the disease. In fact, the lack of neuronal TUNEL labeling in grade 0 cases, the moderate neuronal labeling of grade 2 cases, and the high percentage of TUNEL-positive neurons in grade 3 and 4 cases argue in favor of an accelerated rate of neuronal death as HD progresses. Such a model would explain the increased total numbers and increased percentage $(\sim 20 \%)$ of dying neurons among all surviving neurons that were observed in the dorsal parts of putamen in late-stage cases of HD, and why this part of the dorsal putamen degenerates earlier than ventral putamen in HD (Dunlap, 1927; McCaughey, 1961).

The time course of neuronal degeneration and TUNEL labeling in the caudate nucleus follow those of dorsal putamen, and the high percentage of TUNEL-positive neurons in these two regions indicates that they die early on. This finding is consistent with previous reports that in early HD as many as $50 \%$ of neurons in the caudate nucleus degenerate (Vonsattel et al., 1985). Unfortunately, no grade 1 cases were available for this study, and TUNEL analysis of the caudate nucleus at all early stages was not possible.

It is interesting to note that in some HD cases, particularly grade 0 and grade 4 cases, there was little TUNEL staining. There are at least two reasons for this finding that are related both to the nature of the apoptotic process as well as the stage of the disease. First, apoptosis is a rapid process, and TUNEL may only detect a subset of the dying neurons at any particular point in time. Second, the rate of cell death may be too low to be detected by TUNEL at two distinct stages of the disease, namely, early on when cell death has not yet begun or is still a slow process or late in the disease when the majority of vulnerable cells have already perished.

Concerning nonstriatal areas in cases of HD, only the previously described cell loss in frontal cortex (Cudkowicz and Kowall, 1990; Hedreen et al., 1991; Sotrel et al., 1991; Heinsen et al., 1994) and in the external segment of the globus pallidus (Lange, 1981) were confirmed by TUNEL. Cell death in the cortex and globus pallidus can be explained in two different ways: it may represent retrograde and anterograde cell degeneration, respectively; or it could reflect intrinsic effects of the abnormal IT-15 gene in those regions. The possibility of anterograde postsynaptic death of neurons in the globus pallidus pars externa is consistent with the now well-recognized death of stri- atal neurons projecting to this region in early HD (Reiner et al., 1988; Albin et al., 1992).

The exact role of the IT-15 defect in the neostriatal cell death remains to be determined. One possibility is that this gene is essential to the function of medium spiny neurons that its structural alteration in HD precipitates cellular events that lead to a tightly regulated cell death program. This mechanism occurs in retinal degenerations caused by mutations in the rhodopsin gene (Portera-Cailliau et al., 1994). Alternatively, the IT-15 gene could be directly involved in the cell death cascade in the striatum, and the genetic defect in HD might lead to abnormal reactivation of the death program in the adult.

\section{Cell death in the QA model}

It has been suggested that excitotoxic cell death following intracerebral injections of QA is not mediated by apoptosis, because internucleosomal DNA fragmentation was not found in this context (Ignatowicz et al., 1991). The present study, however, shows that apoptotic DNA laddering does occur in vivo in the first few hours following intrastriatal injection of QA. At later time points, DNA migrated as a smear, suggesting that a necrotic component of cell death was also present. Ultrastructurally, neurons displayed a necrotic morphology, and, at the postinjection time points studied, no apoptotic profiles of any cell type were observed. One possible explanation is that internucleosomal DNA fragmentation is a common early step in all types of cell death and, depending on whether proteases are released, apoptosis or necrosis is the final outcome (Fig. 6, top). In necrosis, because of overall cell swelling, the membrane integrity of neurons might be compromised at some point after the activation of endonucleases so that release of proteases from disrupted lysosomes leads to histone degradation. The result is that DNA is accessible to endonuclease digestion such that a "smear" of DNA is ultimately seen on agarose gel electrophoresis.

The second possibility is that necrosis and apoptosis are two distinct extremes of cell death with different ultrastructural morphologies and DNA fragmentation patterns (Fig. 6, bottom). It is possible, however, that apoptotic and necrotic mechanisms of cell death may coexist (i.e., occur simultaneously) within individual degenerating cells in the excitotoxic model, but ultrastructurally the apoptotic morphology is masked by the rapid necrotic lysis of the cells. The second possibility is supported by preliminary evidence that glucose or oxygen-glucose deprivation induces necrosis and apoptosis simultaneously in cultured cortical neurons (Gwag et al., 1994).

It is noteworthy that, in a model of neuronal death closely related to excitotoxicity (i.e., anoxic-ischemic injury), both apoptotic DNA laddering (Tominaga et al., 1993) and necrotic ultrastructural changes (Deshpande et al., 1992) have been observed. It is possible that similar mechanisms of cell death occur in excitotoxic and anoxic-ischemic injuries.

Double-labeling experiments using TUNEL and antibodies to MBP and GFAP showed that oligodendrocytes and astrocytes are apparently unaffected by the excitotoxin. It is possible that dying cells may not express these phenotypic markers. However, at least in the case of oligodendrocytes, TUNEL-positive nuclei were not observed within the striatal fiber bundles or in the globus pallidus and substantia nigra. The previous finding suggests that oligodendrocytes do not die as a result of a direct action of the toxin or of Wallerian degeneration of striatal efferent axons. In addition, the uniform size of all TUNEL-labeled nuclei is consistent with the death of a single cell type. The death 
MODEL 1

\section{Endonuclease(s)}

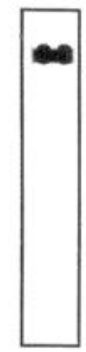

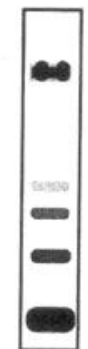

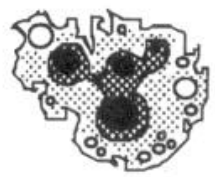

\section{APOPTOSIS}

Histones intact

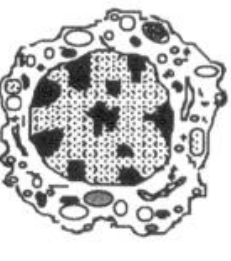

NECROSIS (e.g. excitotoxicity)

Histones degraded

\section{MODEL 2}

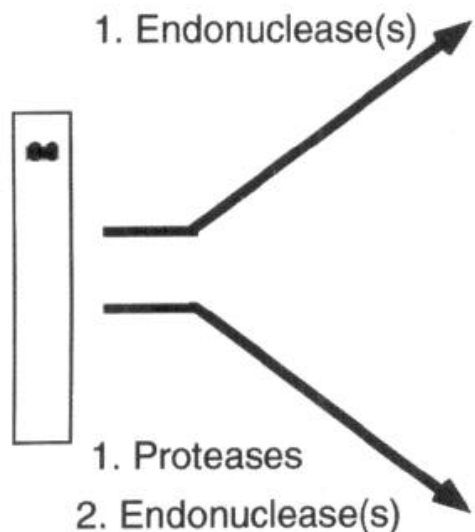

2. Endonuclease(s)

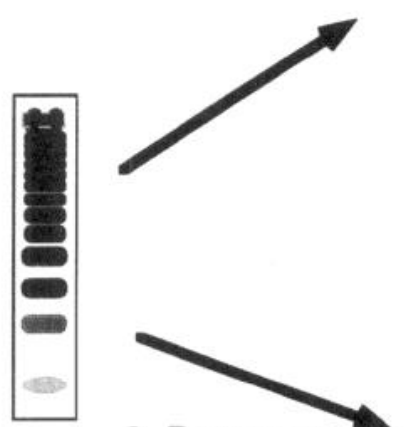

2. Proteases
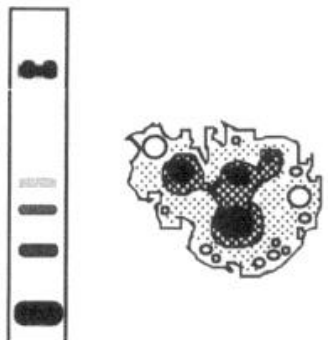

\section{APOPTOSIS}
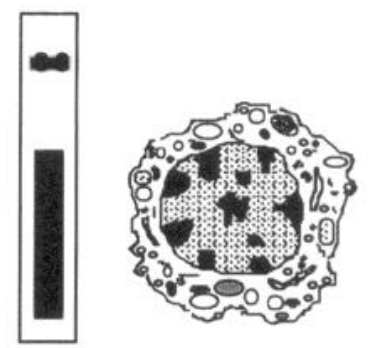

\section{EXCITOTOXICITY}

Apoptosis

and

Necrosis
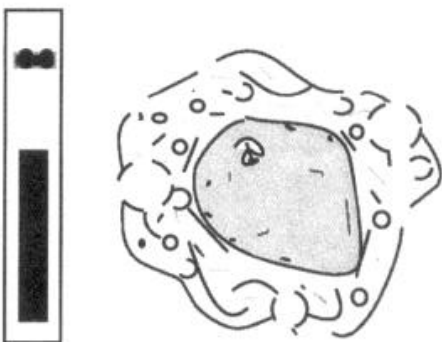

NECROSIS

Figure 6. Top, DNA laddering is a common early step to all types of cell death. The initial event in cell death appears to be the activation of endonuclease(s) that generates a ladder of DNA fragments of high molecular weight. In apoptosis, this degradation goes uninterrupted until most of the DNA is fragmented into mononucleosomes, which are DNA fragments protected from further endonuclease digestion by intact histone octamers. In contrast, release of proteases from disrupted lysosomes follows at some time after endonuclease activation in necrosis leading to degradation of the protective histones and full exposure of the DNA to the endonuclease. This exposure results in random DNA degradation seen as a "smear" on agarose gel electrophoresis. Bottom, Apoptosis and necrosis occur simultaneously in excitotoxicity. The second possibility is that necrosis and apoptosis are two extremes of cell death with different ultrastructural morphologies and DNA fragmentation patterns. In excitotoxic injury, both types of cell death occur simultaneously within individual affected neurons, as evidence by the DNA fragmentation patterns, but ultrastructurally the apoptotic morphology is masked by the overriding necrotic lysis of the neurons. 
of neurons was confirmed by EM (presence of intact synapses on necrotic cells) and by the presence of Wallerian degeneration in striatopallidonigral fibers.

The time course of neuronal degeneration in the QA model occurs between $10 \mathrm{hr}$ and $5 \mathrm{~d}$ after a single injection. Because all neurons near the injection site dic synchronously, the above observation suggests that the survival of a cell following an excitotoxic insult extends to a few days. Therefore, necrosis proceeds more slowly than apoptotic cell death, which has an estimated duration on the order of a few hours (Kerr and Harmon, 1991; Arends et al., 1990; Bursch et al., 1990; Pittman et al., 1993). TUNEL staining in the QA model appears concomitantly with the DNA laddering stage but persists beyond it, lasting longer than the actual apoptotic process.

\section{$H D$ and excitotoxic animal models}

An important goal of the present study was to test the reliability of excitotoxic animal model of HD. A number of similarities exist between this model and the human disease with respect to neuronal cell death. For example, in both settings, as evidenced by TUNEL, medium spiny neurons die selectively among other populations of striatal neurons. Also in the QA model, DNA undergoes fragmentation in a nucleosomal pattern in the first few hours of excitotoxic damage, a development that coincides with the appearance of TUNEL staining in the striatum. On the other hand, some grade $3 \mathrm{HD}$ cases showed evidence of nonrandom DNA fragmentation. The above two observations suggest that an apoptotic mechanism of cell death is active in both settings.

There are many differences, however, between HD and the excitotoxic model. The slow and insidious progression that affects isolated neuronal as well as oligodendrocytes in HD is unlike the rapid and massive degeneration that is selective for neurons in the QA model. These differences indicate the limitations of the acute excitotoxic injury as a model of the neurodegeneration in HD with regard to the exact mechanisms of cell death. It remains to be explored whether cumulative toxicity following chronic infusions of subtoxic levels of QA can lead to features of neuronal cell death that more closely resemble those seen in HD.

\section{Distinction between different types of cell death in the nervous} system

The present study has addressed several important issues regarding the methods currently used to distinguish between different types of cell death. The results of the present study indicate that, in order to study the exact mechanisms of cell death in a particular model, investigators have to use multiple techniques throughout the time course of the death process. For example, cell death following excitotoxic lesions can exhibit a necrotic morphology at the same time (10-16 hr postinjection) that apoptotic DNA laddering is observed by agarose gel electrophoresis, but, at a later time, only necrotic DNA smearing can be observed. In one report, DNA laddering was not detected 16 hr following excitotoxic lesions, and cell death was assumed to be entirely necrotic (Ignatowicz et al., 1991).

Although the TUNEL method is not always a reliable marker for apoptotic cell death (as cells in tissues exhibiting DNA smearing can be labeled), patterns of TUNEL labeling can often be suggestive of apoptotic cell death. For example, the multifocal single cell death detected by TUNEL in HD is indicative of apoptosis and is highly reminiscent of that seen in naturally occurring cell death in the retina (Chang et al., 1993; PorteraCailliau et al., 1994), cerebellum (Wood et al., 1993), and cortex (Portera-Cailliau and Koliatsos, personal observations).

Agarose gel electrophoresis proved to be less sensitive than TUNEL in detecting DNA fragmentation in tissues with few dying cells (such as in HD). On the other hand, in tissues with extensive cell death (e.g., the QA model), agarose gel electrophoresis was actually more sensitive than TUNEI, detecting DNA fragmentation at least $2 \mathrm{hr}$ before the beginning of TUNEL labeling. However, the specificity of DNA electrophoresis in distinguishing apoptosis from necrosis remains to be determined (Collins et al., 1992). If these two types of cell death share an intermediate step of DNA laddering, as proposed in our model, then the presence of internucleosomal DNA fragmentation should no longer be considered a hallmark of apoptosis. It may be that ultrastructural morphology is the only reliable and unequivocal marker of the type of cell death in the nervous system.

\section{References}

Albin RL, Reiner A, Anderson KD, Dure LS, IV, Handelin B, Balfour R, Whetsell WO, Penney JB, Young AB (1992) Preferential loss of striato-external pallidal projection neurons in presymptomatic Huntington's disease. Ann Neurol 31:425-430.

Appel SH (1981) A unifying hypothesis for the cause of amyotrophic lateral sclerosis, parkinsonism, and Alzheimer disease. Ann Neurol 10:499-505.

Arends M.I, Morris RG, Wyllie AH (1990) Apoptosis. The role of the endonuclease. Am J Pathol 136:593-608.

Beal MF, Kowall NW, Ellison DW, Mazurek MF, Swartz KJ, Martin JB (1986) Replication of the neurochemical characteristics of Huntington's disease by quinolinic acid. Nature 321:168-171.

Beal MF, Kowall NW, Swartz KJ, Ferrante RJ, Martin JB (1989) Differential sparing of somatostatin-neuropeptide $Y$ and cholinergic neurons following striatal excitotoxin lesions. Synapse 3:38-47.

Bursch W, Paffe S, Putz B, Barthel G, Schulte-Hermann R (1990) Determination of the length of the histological stages of apoptosis in normal liver and in altered foci of rats. Carcinogenesis 11:847-853.

Chang G-Q, Hao Y, Wong F (1993) Apoptosis: final common pathway of photoreceptor death in $r d, r d s$, and rhodopsin mutant mice. Neuron 11:595-605.

Collins RJ, Harmon BV, Gobe GC, Kerr JFR (1992) Internucleosomal DNA cleavage should not be the sole criterion for identifying apoptosis. Int J Radiat Biol 61:451-453.

Coyle JT, Schwarcz R (1976) Lesion of striatal neurones with kainic acid provides a model for Huntington's chorea. Nature 263:244-246.

Cudkowicz M, Kowall NW (1990) Degeneration of pyramidal projection neurons in Huntington's disease cortex. Ann Neurol 27:200-204.

Deshpande J, Bergstedt K, Linden T, Kalimo H, Wieloch T (1992) Ultrastructural changes in the hippocampal $\mathrm{CA} 1$ region following transient cerebral ischemia: evidence against programmed cell death. Exp Brain Res 88:91-105.

Dunlap CB (1927) Pathologic changes in Huntington's chorea. With special reference to the corpus striatum. Arch Neurol Psychiatry 18: 867-943.

Ellis RE, Yuan J, Horvitz HR (1991) Mechanisms and functions of cell death. Annu Rev Cell Biol 7:663-698.

Freeman RS, Estus S, Horigome K, Johnson EM Jr (1993) Cell death genes in invertebrates and (maybe) vertebrates. Curr Opin Neurobiol 3:25-31

Gavrieli Y, Sherman Y, Ben-Sasson SA (1992) Identification of programmed cell death in situ via specific labeling of nuclear DNA fragmentation. J Cell Biol 119:493-501.

Goto K, Ishige A. Sekiguchi K, Iizuka S, Sugimoto A. Yuzurihara M, Aburada M, Hosoya E, Kogure K (1990) Effects of cycloheximide on delayed neuronal death in rat hippocampus. Brain Res 534:299_ 302.

Gwag BJ, Lobner D, Koh J, Wie MB, Choi DW (1994) Blockade of glutamate receptors during oxygen or glucose deprivation unmasks apoptosis in cultured cortical neurons. Soc Neurosci Abstr 20:248.

Hedreen JC, Peyser CE, Folstein SE, Ross CA (1991) Neuronal loss 
in layers V and VI of cerebral cortex in Huntington's disease. Neurosci Lett 133:257-261.

Heinsen H, Strik M, Bauer M, Luther K, Ulmar G, Gangnus D, Jungkunz G, Eisenmenger W, Götz. M (1994) Cortical and striatal neurone number in Huntington's disease. Acta Neuropathol 88:320-333.

Huntington's Disease Collaborative Research Group (1993) A novel gene containing a trinucleotide repeat that is expanded and unstable on Huntington's disease chromosomes. Cell 72:971-983.

Ignatowicz E, Vezzani A-M, Rizzi M, D'Incalci M (1991) Nerve cell death induced in vivo by kainic acid and quinolinic acid does not involve apoptosis. Neuroreport 2:651-654.

Kerr JFR, Harmon BV (1991) Definition and incidence of apoptosis: an historical perspective. In: Apoptosis (Tomei LD, Cope HO, eds), pp 5-29. Cold Spring Harbor, NY: Cold Spring Harbor Laboratory.

Kerr JFR, Wyllie AH, Currie AR (1972) Apoptosis: a basic biological phenomenon with wide-ranging implications in tissue kinetics. $\mathrm{Br} \mathbf{J}$ Cancer 26:239-257.

Kowall NW, Ferrante RJ, Martin JR (1987) Patterns of cell loss in Huntington's disease. Trends Neurosci 10:24-29.

Kure S, Tominaga T, Yoshimoto T, Tada K, Narisawa K (1991) Glutamate triggers internucleosomal DNA cleavage in neuronal cells. Biochem Biophys Res Commun 179:39-45.

Lange HW (1981) Quantitative changes of telencephalon, diencephalon, and mesencephalon in Huntington's chorea, postencephalitic, and idiopathic parkinsonism. Vehr Anat Ges 75:923-925.

McCaughey WTE (1961) The pathologic spectrum of Huntington's chorea. J Nerv Ment Dis 133:91-103.

McGeer EG, McGeer PL (1976) Duplication of biochemical changes of Huntington's chorea by intrastriatal injections of glutamic and kainic acids. Nature 263:517-519.

Obeid LM, Linardic CM, Karolak LA, Hannun YA (1993) Programmed cell death induced by ceramide. Science 259:1769-1771.

Oppenheim RW (1991) Cell death during development of the nervous system. Annu Rev Neurosci 14:453-501.

Pcitsch MC, Polzar B, Stephan H, Crompton T, MacDonald HR, Man nherz HG, Tschopp J (1993) Characterization of the endogenous deoxyribonuclease involved in nuclear DNA degradation during apoptosis (programned cell dealh). EMBO J 12:371-377.

Pittman RN, Wang S, DiBenedetto AJ, Mills JC (1993) A system for characterizing cellular and molecular events in programmed neuronal cell death. J Neurosci 13:3669-3680.
Portera-Cailliau C, Sung C-H, Nathans J, Adler R (1994) Apoptotic photoreceptor cell death in mouse models of retinitis pigmentosa. Proc Natl Acad Sci USA 91:974-978.

Rahacchi SA, Bonfanti L, Liu X-H, Maffei L (1994) Apoptotic cell death induced by optic nerve lesion in the neonatal rat. J Neurosci 14:5292-5301.

Reiner $\Lambda, \Lambda$ lbin RL, Anderson KD, D' $\Lambda$ mato CJ, Penney JB, Young AB (1988) Differential loss of striatal projection neurons in Huntington disease. Proc Natl Acad Sci USA 85:5733-5737.

Schwartz LM, Smith SW, Jones MEE, Osborne BA (1993) Do all programmed cell deaths occur via apoptosis? Proc Natl Acad Sci USA 90:980-984.

Sotrel A, Paskevich PA, Kiely DK, Bird ED, Williams RS, Myers RH (1991) Morphometric analysis of the prefrontal cortex in Huntington's disease. Neurology 41:1117-1123.

Surh CD, Sprent J (1994) T-Cell apoptosis detected in situ during positive and negative selection in the thymus. Nature 372:100-103.

Tominaga T, Kure S, Narisawa K, Yoshimoto T (1993) Endonuclease activation following focal ischemic injury in the rat brain. Brain Res 608:2I-26.

Veis DJ, Sorenson CM, Shutter JR, Korsmeyer SJ (1993) Bcl-2-deficient mice demonstrate fulminant lymphoid apoptosis polycystic kidneys and hypopigmented hair. Cell 75:229-240.

Vonsaltel J-P, Myers RH, Stevens TJ, Ferrante RJ, Bird ED, Richardson EP Jr (1985) Neuropathological classification of Huntington's disease. J Neuropathol Exp Neurol 44:559-577.

White K, Grether ME, Abrams JM, Young L, Farrell K, Steller H (1994) Genetic control of programmed cell death in Drosophila. Science 677-683.

Wood KA, Dipasquale B, Youle RJ (1993) In situ labeling of granule cells for apoptosis-associated DNA fragmentations reveals different mechanisms of cell loss in developing cerebellum. Neuron 11:621632.

Wouterlood FG, Bol JGJM, Steinbusch HWM (1987) Double-label immunocytochemistry: combination of anterograde neuroanatomical tracing with Phaseolus vulgaris leucoagglutinin and enzyme immunocytochemistry of target neurons. J Histochem Cytochem 35:817823.

Wyllie AH (1980) Glucocorticoid-induced thymocyte apoptosis is associated with endogenous endonuclease activation. Nature 284:555556. 